Revista Eletrônica do Mestrado

Profissional em Administração da UnP

\title{
edUnp
}

V. 11, N. 2, 2019

ISSN 1984-4204

https://repositorio.unp.br/index.php/raunp

https://doi.org/10.21714/raunp.v11i2.2077

\section{Aprendizagem e desenvolvimento gerencial: percepções dos gestores de uma instituição financeira em Pernambuco}

\section{Learning and management development: perceptions of the managers of a financial institution in Pernambuco}

\author{
Diogo Henrique Helal ${ }^{\mathrm{a}}$, Leandro Ledo de Lima ${ }^{\mathrm{b}}$ \\ ${ }^{\text {a }}$ Professor do Mestrado Profissional em Gestão Empresarial do UniFBV|Wyden. diogohh@yahoo.com.br \\ b Graduado em Administração de Empresas. Universidade Federal de Pernambuco, UFPE-CAA, Brasil. leo.ledo@hotmail.com
}

\begin{abstract}
Resumo
Analisa-se a aprendizagem em um programa de desenvolvimento gerencial do Banco X, a partir da compreensão dos novos gerentes, que atuam em agências do Estado de Pernambuco. A revisão de literatura discute desenvolvimento gerencial, aprendizagem e competências gerenciais. Apresenta uma retrospectiva histórica sobre aprendizagem nas organizações, bem como pesquisas sobre o tema. A metodologia se baseia em estudo de caso, analisando um programa de desenvolvimento gerencial do Banco X, com base na teoria da aprendizagem experiencial de Kolb (1984) e Kolb e Kolb (2017). A coleta de dados ocorreu por meio de entrevistas em profundidade com gerentes participantes da Oficina Gestores em Primeira Investidura. Na análise dos dados, foi possível comparar o entendimento dos gestores sobre o programa de desenvolvimento, e os objetivos da empresa com o programa. Os resultados da pesquisa apontam para o papel das experiências diárias, relacionamentos e da aprendizagem formal, como promotores do aprendizado dos gestores.
\end{abstract}

Palavras-chave: desenvolvimento gerencial; aprendizagem experiencial; gerentes.

\begin{abstract}
This article analyzes the learning in a managerial development program of Banco X, from the understanding of the company and the new managers, who work in agencies of the State of Pernambuco, Brazil. The literature review discusses managerial development, learning, and management skills. It also presents a historical retrospective on learning in organizations. The methodology is based on a case study, analyzing a managerial development program of Bank X, based on the theory of experiential learning by Kolb (1984) and Kolb and Kolb (2017). Data collection through in-depth interviews with managers, participants of the Managers Workshop at First Investiture. In the data analysis, it was possible to compare the managers' understanding of the development program studied and the company's objectives with the program. The results of the research point to the role of daily experiences, relationships and formal learning as promoters of managers' learning.
\end{abstract}

Keywords: managerial development; experiential learning; managers. 


\section{Introdução}

Aprendizagem gerencial é um tema que vem ganhado destaque no meio acadêmico brasileiro nos últimos anos. Com a necessidade de se criar mecanismos eficientes por meio dos quais os executivos possam lidar com os desafios diários de seus trabalhos, a aprendizagem gerencial, segundo Moraes, Silva e Cunha (2004), apresenta-se como um campo emergente de pesquisa. Antonello et al (2011), contudo, alertam sobre a pouca quantidade de publicações sobre o tema no cenário brasileiro.

Discutir a aprendizagem gerencial remete à discussão da função gerencial em si, que é caracterizada por um contexto de variabilidade e incertezas. Com vistas a gerir tais incertezas, e buscando capacitar e preparar seu corpo de funcionários para atividades de liderança e decisão, as empresas tem investido mais e mais em programas de desenvolvimento gerencial. Este tipo de investimento, segundo Mapurunga et al. (2016), tende a resultar em desenvolvimento organizacional.

Tal resultado é estratégico para as organizações em geral, e em particular aquelas inseridas em contexto de forte competição, como o existente no setor bancário brasileiro. Este setor, no Brasil, nas últimas décadas, tem passado por profundas mudanças e incertezas, decorrentes de forte inserção de tecnologia, fusões e aquisições e aumento de competitividade. Segundo Pereima Neto e Pauli (2008), estas transformações envolveram as inovações em produtos e serviços, práticas de gestão e governança, estratégias de mercado, regras na formação de preços de serviços e operações, gestão de ativos e passivos, fusões e aquisições, e a entrada de bancos estrangeiros. Tal contexto tem demandado o desenvolvimento de novas competências dos profissionais que se inserem nesse setor.

$\mathrm{Na}$ tentativa de fornecer aos gerentes meios de desenvolverem suas competências, as empresas se valem de programas específicos de formação e desenvolvimento gerencial, com foco em um processo de aprendizado dinâmico e contínuo. Para se compreender melhor esse processo, este artigo se vale da teoria da aprendizagem experiencial (Kolb, 1984; Kolb \& Kolb, 2017). Nesta abordagem teórica, o aprendizado de competências é visto como fruto da reflexão sobre as situações vividas no cotidiano da gestão. Leite (2011) acredita que o local de trabalho é capaz de aumentar e suplementar a educação formal, além de desenvolver o profissional.

Um estudo relevante e seminal sobre aprendizagem gerencial foi desenvolvido por Linda Hill (1993). Já na década de 1990, a autora considerava que a aprendizagem gerencial ocorria predominantemente por meio das experiências no trabalho. Assim, acreditava que os investimentos organizacionais focados em educação e desenvolvimento formais eram limitados (Hill, 1993).

Buscando contribuir com esse debate, o presente trabalho objetiva analisar, com base no modelo de aprendizagem experiencial de Kolb (1984) e Kolb e Kolb (2017), como se dá o processo de aprendizagem na percepção de gestores de uma instituição financeira em Pernambuco.

\section{Referencial Teórico}

\subsection{Aprendizagem gerencial}

Comumente, a aprendizagem de gerentes é entendida como fruto do desenvolvimento gerencial por meios formais. Esta compreensão decorre da visão tradicional de aprendizagem como transferência de conhecimentos (Moraes, Silva \& Cunha, 2004). Observa-se, também, que a teoria e prática na área de aprendizagem gerencial tem recebido influência de abordagens da educação e aprendizado de adultos. 
Neste sentido, é de se esperar que as experiências no local de trabalho sejam consideradas no processo de aprendizagem dos gestores. Tal processo ocorre em situações formais e informais, durante a prática do trabalho, no dia-a-dia, em momentos não planejados, e também por meio dos relacionamentos construídos pelos gestores (Moraes, Silva \& Cunha, 2004).

Sobre a função gerencial, Mintzberg (2010) afirma que esta não pode ser ensinada, sendo, portanto, aprendida no trabalho e aperfeiçoada por meio da experiência. No mesmo caminho, enfatizando o caráter único da aprendizagem gerencial, Hill (1993, p.211) considera que "o desenvolvimento da gerência é uma proposição paradoxal. Os que tem essa responsabilidade não podem dizer aos novos gerentes o que eles precisam saber, mesmo que saibam o que dizer aos gerentes".

Quanto ao caráter único desta aprendizagem, D’Amelio (2011) ressalta que para esse grupo, as expectativas sobre suas atuações (e a experiência em si) se sobrepõem aos conhecimentos da área de administração, exigindo dos gestores habilidades e atitudes que lhe permitam lidar com a complexidade do meio empresarial. Isso somente é possível mediante a um processo contínuo de aprendizado. Closs e Antonello (2011) lembram que tal complexidade decorre da desordem e incertezas do mundo atual, da saturação de informações e de incessantes mudanças tecnológicas e transformações sociais.

Analisar, portanto, a aprendizagem de competências gerenciais requer a habilidade de entender o contexto em que o gestor está inserido, bem como suas particularidades. Cumpre lembrar que a gestão aqui é compreendida como "uma prática, aprendida principalmente com a experiência e enraizada no contexto" (Mintzberg, 2010, p.23). Para se estudar o contexto da aprendizagem dos gestores, este estudo optou pelo modelo de aprendizagem experiencial de Kolb e Kolb (2017), apresentado a seguir.

\subsection{Modelo da aprendizagem experiencial de Kolb (1984)}

Hill (1993, p.207), ao entrevistar um grupo de gerentes, declarou: “eles acharam muito fácil aprender a partir da experiência, quando tinham fortes relacionamentos de desenvolvimento com superiores e colegas, quando recebiam avaliações honestas e imediatas sobre seu desempenho". Isso ilustra a riqueza das experiências vividas no exercício da função gerencial, sendo este um importante ambiente de desenvolvimento de competências, habilidades e atitudes. Vale ressaltar que essas experiências não se limitam às experimentadas no contexto do trabalho, mas também nas diversas esferas da vida do indivíduo (Silva, 2008).

Uma das obras mais citadas no campo da aprendizagem experiencial é a "Experiencial Learning: experience as the source of learning and development" publicada em 1984 por David Kolb. Esta obra ressalta as experiências como o elemento central no processo de aprendizagem, e considera que a reflexão ativa sobre essas experiências vividas torna o aprendizado efetivo.

Kolb (1984) entende que observar a aprendizagem experiencial como um conjunto de técnicas e métodos é limitada. Por outro lado, a sua teoria seria uma forma de enxergar o papel da reflexão consciente no processo de aprendizagem. Kolb (1984) considera que desde recém-nascidos nos tornamos partes de um processo constante de aprendizado por meio de nossas experiencias, sendo nossas ideias e pensamentos reformados através delas.

A aprendizagem experiencial, segundo o modelo apresentado por Kolb (1984) e por Kolb e Kolb (2017) segue alguns princípios:

- A aprendizagem é melhor entendida como processo e não como um resultado, não podendo ser evidenciada unicamente por meio de desempenho. E como processo, assume o caráter contínuo diante 
da mutabilidade humana, que passa a enxergar as coisas por novas óticas de acordo com as experiências vivenciadas;

A aprendizagem é fundamentada na experiência; sendo assim cada nova experiência produz um reaprendizado. Experiencias passadas influenciam diretamente a nossa forma de enxergar as futuras;

- Conflitos, diferenças e desacordos são os combustíveis da aprendizagem. São essas tensões criadas diante de novas experiências que provocam a reflexão, levando o indivíduo a interpretar a situação e entendê-la;

- $\quad$ A aprendizagem é o principal processo de adaptação humana ao mundo à sua volta;

- $\quad$ O aprendizado é resultado de transações entre indivíduos e meio ambiente, entre experiências objetivas e subjetivas;

- $\quad$ Existe uma relação estreita entre a aprendizagem e a geração de conhecimento.

Moraes, Silva e Cunha (2004) consideram que os gestores vivenciam momentos de aprendizagem ao longo da sua prática de trabalho, e durante sua trajetória profissional, sendo inadequado compreender que a aprendizagem ocorra em momentos isolados.

Neste sentido, Kolb (1984) e Kolb e Kolb (2017) apresentam o conceito do ciclo da aprendizagem experiencial, quando definem o conhecimento como resultado da apreensão e transformação da experiência. Para Sonnentag et al. (2004), o processo de apreensão se dá por meio da experiencia e da conceitualização abstrata, enquanto transformação ocorre no processo de reflexão e experimentação ativa.

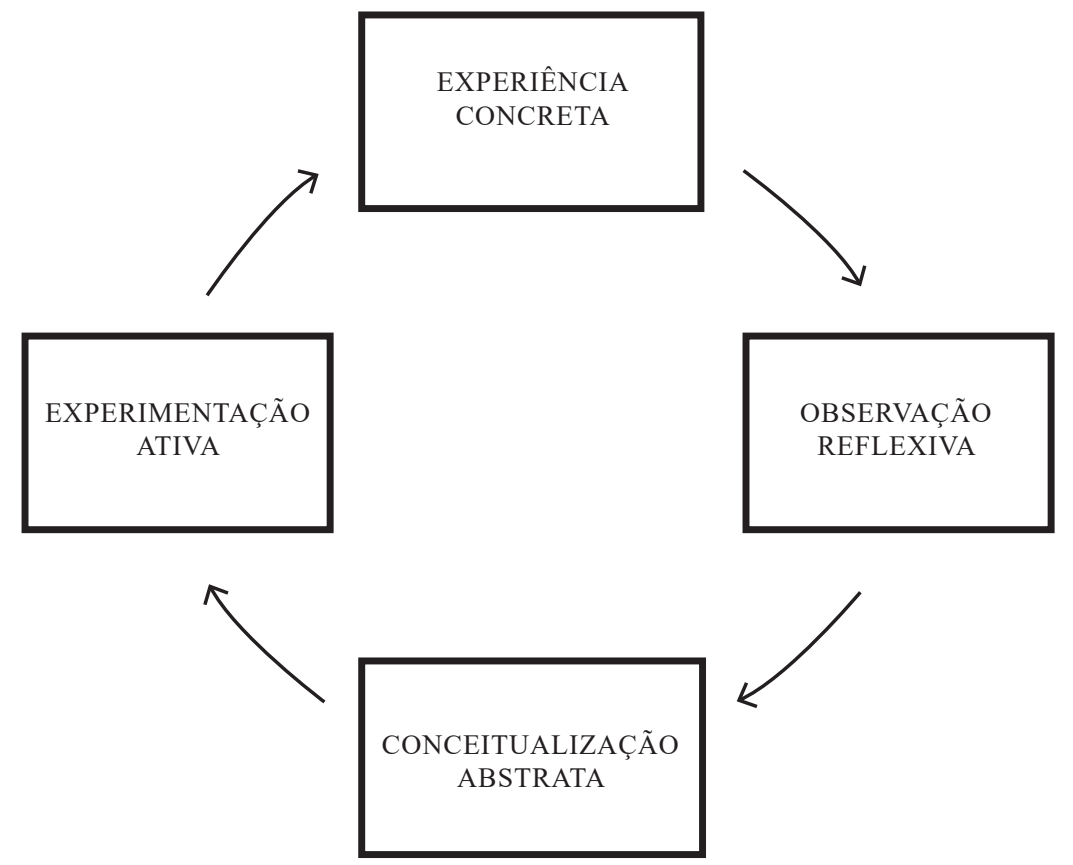

Fig. 1: Ciclo de aprendizagem de Kolb (1984) e Kolb e Kolb (2017)

Fonte: elaborado a partir de Kolb (1984) e Kolb e Kolb (2017).

A aprendizagem experiencial é, assim, entendida como um processo em que o indivíduo reflete sobre sua experiência e a partir desta, aprende (Antonello, 2011). A aprendizagem, nesta perspectiva, inicia pela experiência concreta e interage com ela.

Silva (2008), em particular, defende que mesmo aquelas experiências não relacionadas ao trabalho 
em si são fontes de aprendizagem. No mesmo sentido, Silva e Rebelo (2006) destacam cinco dimensões que influenciam o aprendizado de gestores: família, escola, comunidade, vida de empregado e vida de gerente. Nicolini (2013, p.35) afirma que "a aprendizagem é vivamente influenciada pela convivência com os seus pares e com os colegas de trabalho em funções correlatas". Continua o autor:

\begin{abstract}
Aprender situadamente implica estar imerso no local de trabalho, em interação com os colegas e desfrutando da legitimidade conferida à posição de aprendiz, que lhe garante um distanciamento das atividades centrais e mais importantes enquanto apreende os conhecimentos necessários para praticar (Nicolini, 2013, p.35).
\end{abstract}

Cumpre destacar que a reflexão é elemento importante na aprendizagem gerencial. A habilidade de refletir sobre o que nos rodeia nos concede meios de moldarmos nossas experiências em aprendizado. Quando as coisas que nos rodeiam começam a fazer sentido, então nos tornamos capazes de controlá-las (Westbrook \& Teixeira, 2010). Reis (2011) destaca que esse esforço em entender e dar sentido às experiências resulta em novas descobertas e apreciações.

Essa possibilidade de refletir é o que dá valor à experiência como promotora de aprendizagem. "A suposição é que raramente se aprende da experiência, a menos que se avalie a experiência, conceba-se o próprio significado em termos das próprias metas, objetivos, ambições e expectativas" (Antonello, 2011, p. 143). Portanto, refletir é o que enriquece nossas experiências com sentido e conhecimento útil.

O próximo passo do ciclo de Kolb (1984) e Kolb e Kolb (2017) diz respeito à conceitualização abstrata. É o momento em que mapas mentais são formados. Segundo Leite (2011), nesta fase os indivíduos podem criar conceitos que integrem suas observações e reflexões em uma teoria. Estas servem de guias para a ação e decidimos de que forma nos lembraremos das experiências.

O ciclo da aprendizagem tem como a última fase a experimentação. É quando o indivíduo, munido no conhecimento adquirido em seu processo de reflexão das experiências vivenciadas, decide como se dará sua ação.

O ciclo de aprendizagem de Kolb (1984) e Kolb e Kolb (2017) fala do processo contínuo de experiências, reflexões, abstração e criação de conceitos e ação. O ciclo permanece em constante repetição, uma vez que novas experiências são influenciadas diretamente pelas percepções e conceitos criados e testados nas experiências anteriores.

Por fim, cabe lembrar que a aprendizagem tem um caráter coletivo, pois ocorre por meio das relações sociais. Santos e Cassandre (2017) destacam que a aprendizagem é construída no coletivo, a partir das interações sociais. A aprendizagem é também "mediada por artefatos físicos e simbólicos e influenciada por uma dupla cultura organizacional, por um juízo estético, por um pensar vinculado ao fazer e por uma capacidade transformadora da própria atividade" (Santos \& Cassandre, 2017, p.170).

Tal perspectiva coletiva é própria da abordagem construtivista de aprendizagem, que enfatiza a experiência, em um processo de aprendizagem em ação. Sobre tal processo, Santos et al (2018, p.80) destacam o seguinte:

Como uma abordagem de desenvolvimento gerencial, a aprendizagem em ação produz mudanças em níveis de experiência individual, interpessoal e gerencial, permitindo que os participantes desenvolvam sua capacidade de ouvir e entender as situações de forma empática, fundamentem suas ações, tomem responsabilidades e tenham iniciativa (Santos et al, 2018, p.80). 


\section{Metodologia}

A pesquisa, a partir de uma perspectiva descritiva e qualitativa, buscou responder como gerentes de uma grande corporação financeira aprendem a função gerencial. Para Gerhard e Silveira (2009), a pesquisa qualitativa permite ter certa profundidade, levantando aspectos da realidade que não podem ser quantificados. Guerra (2014) afirma que a pesquisa qualitativa nos ajuda a considerar aspectos da subjetividade humana. Esta pesquisa é também descritiva, pois tem a intenção de extrair opiniões, atitudes, percepções e crenças de determinada população (Gil, 2002).

Os sujeitos da pesquisa são gerentes gerais de agência varejo de uma grande instituição financeira nacional. Todos os gestores entrevistados atuavam em municípios localizados no agreste pernambucano. Ao total foram sete gerentes entrevistados em profundidade, selecionados por acessibilidade e tipicidade, sendo seis homens e apenas uma mulher, todos com menos de três anos na função, e que tivessem já participado da Oficina Gestores em Primeira Investidura, oferecida pelo banco.

Vale a pena ressaltar aqui que a instituição financeira em questão é um grande conglomerado financeiro brasileiro, atuante em mais de 23 países, e em 2017 possuía mais de 100 mil funcionários. Tal banco possui um programa consolidado de desenvolvimento de liderança.

O roteiro de entrevistas tomou como referência o utilizado por Linda Hill (1993), que buscou entender como gerentes se desenvolvem e em que recursos se baseiam no processo de aprendizado.

Tal roteiro foi pré-testado com um sujeito elegível para a pesquisa, e depois modificado e ajustado, buscando conferir maior clareza a ele.

As entrevistas foram realizadas em janeiro de 2018. Os sujeitos foram contatados inicialmente por e-mail, quando se apresentou a pesquisa e seus objetivos, e se fez o convite para a realização das entrevistas. As entrevistas foram agendadas e realizadas presencialmente. Com o intuito de preservar a identidade dos participantes, o nome dos mesmos foi suprimido nesta pesquisa, sendo identificados, nesta pesquisa, por números de 1 ao 7. Na sétima entrevista entendeu-se que havia se chegado à saturação das respostas, sendo este o número final de entrevistados.

Os dados obtidos durante a pesquisa foram trabalhados por meio da análise de conteúdo temática, tendo em vista que a partir dela é possível a "interpretação de material de caráter qualitativo, assegurando uma descrição objetiva, sistemática e com riqueza manifesta no momento da coleta dos mesmos" (Guerra, 2014, p. 38). Esta forma de análise é comumente constituída de 3 fases - pré-análise, exploração e tratamento (Gil, 2002) - aqui devidamente adotadas.

A pré-análise ocorreu a partir da preparação do material a ser analisado por meio de leitura. A exploração do material se deu a partir da escolha das unidades, com numeração e classificação das mesmas em categorias. O tratamento dos dados consistiu na análise e interpretação dos resultados.

Do ponto de vista prático, seguiu-se o passo-a-passo apresentado por Gerhardt e Silveira (2009): as entrevistas foram transcritas, e a análise tomou como base a leitura das falas. A partir deste momento estruturas com significados relevantes foram agrupadas em categorias para posterior análise e interpretação.

\section{Análise dos dados}

Durante as entrevistas os gestores foram convidados a discorrer sobre suas percepções quanto ao papel que desempenham e como aprenderam as competências demandadas em suas atividades.

Observou-se que, via de regra, o caminho percorrido pelos participantes até atingirem a função de 
gerencial geral foi bastante parecido. A entrada na instituição financeira se deu pelo posto de escriturário, e a ascensão de cargos os levou a assistente de gerente, gerente de nível médio, para finalmente chegar à gerência geral.

Quando inquiridos sobre o significado da atuação gerencial, os relatos convergiram para uma única palavra: responsabilidade. Para os gestores entrevistados, gerenciar é assumir a responsabilidade de gerir negócios, pessoas e o operacional das agências onde estão inseridos:

"Gerente geral dentro da unidade do banco é responsável por toda parte operacional e negocial do banco, em todos os seus detalhes" (E1).

“É o seguinte, gerir negócios é a principal função hoje da gente. Com o objetivo de rentabilizar carteiras e gerir processos e pessoas, basicamente isso" (E5).

Essa representação da função gerencial é coerente com a apresentada por Mintzberg (2010), que considera o gerente como o responsável por toda uma organização, ou por parte dela.

A prática gerencial foi apresentada pelos entrevistados de forma variada. Cada um dos gerentes tinha opinião própria do que comporia o tema. Tal resultado vai no encontro do defendido por Mintzberg (2010), que considera que a gestão não é unicamente uma ciência, uma vez que muito do trabalho gerencial é intuitivo.

Assim, observou-se que as experiências individuais dos entrevistados moldaram as diversas formas de eles perceberem suas atuações enquanto gerentes. Ao caracterizar sua prática gerencial, os entrevistados mencionaram palavras como: sacrifício, paciência, gerenciamento de pessoas, foco, planejamento, calma diante das adversidades, planejamento, proatividade, conhecimento dos normativos e aprendizado contínuo.

Destaca-se que a necessidade de gerir pessoas surgiu como ponto comum à maioria dos entrevistados, conforme se vê no relato a seguir: "Primeiro pessoas. Você tem que ter um grande histórico em relacionamento de pessoas de todos os tipos" (E3).

O conhecimento dos normativos, citado em diversos relatos, é algo inerente aos trabalhadores dessa instituição financeira, sendo fortemente associado ao exercício da função gerencial. Os relatos indicaram que, nos últimos anos, diversos funcionários foram punidos por descumprimento das normas estabelecidas pela empresa.

Quanto à aprendizagem da função gerencial, buscou-se entender, inicialmente, o papel da educação formal nesse processo. Entende-se aqui que educação formal corresponde àquela adquirida por meio da graduação, pós-graduação e cursos de aperfeiçoamento.

Todos os sujeitos entrevistados possuíam curso superior, predominando os voltados a ciências sociais aplicadas, como: economia e ciências contábeis. Dentre os gestores entrevistados, somente dois não possuíam qualquer tipo de pós-graduação. Aqueles que a possuíam afirmaram que a busca por ela se deu a partir da necessidade de complementar seus conhecimentos sobre a função gerencial. Todos observaram como positivo o papel da educação formal no processo de aprendizagem gerencial: "Para mim o MBA foi um divisor de águas; segmentou muita coisa que via que estava bom, expurgou também o que estava errado, que não era o jeito de trabalhar" (E3).

O entendimento do papel que a educação formal desempenha no processo de aprendizagem gerencial é apontado também por Linda Hill (1993), Leite (2011), Silva (2008) e D’Amelio (2011). Os gestores entrevistados enfatizaram principalmente o papel dos cursos de pós-graduação no processo de aprendizagem. Os cursos de graduação, apesar de serem vistos como importantes, foram menos ressaltados. Para os sujeitos, a formação em pós-graduação trouxe conhecimentos significativos para a sua prática como gestores. 
Apesar da relevância dada à educação formal, Hill (1993) descreve o treinamento formal como limitado quando se trata da aprendizagem gerencial. Leite (2011) complementa esse pensamento ao afirmar que no desenvolvimento de competências gerenciais, além dos cursos formais é necessário experiências gerenciais e profissionais. Segundo Antonello (2011, p.242), "pode-se dizer que o desenvolvimento de uma competência gerencial específica não é um mero produto de processos e formas de aprendizagem particulares”.

Os gestores entrevistados foram unânimes em concordar que apesar do valor da educação formal no processo de aprendizagem, muito do que aprenderam veio das experiências do dia-a-dia na função. A prática trouxe consigo os elementos necessários para seu aprendizado.

Hill (1993) já apresentava este dilema de constante aprendizado ao qual gerentes são submetidos durante sua labuta laboral: "as lições eram assimiladas à medida que os gerentes enfrentavam a ladainha diária de interações e problemas em sua nova designação" (Hill, 1993, p. 7).

De outra parte, Kolb (1984) e Kolb e Kolb (2017) lembram que a aprendizagem é o principal processo de adaptação humana. Os gerentes, sujeitos dessa pesquisa, apresentaram afirmativa semelhante, como pode ser observado nas falas a seguir:

"No dia a dia você vai aprendendo também. Setenta por cento é dia a dia. Você vai aprendendo com as pessoas e com seus erros e acertos" (E5).

"Porque eu costumo dizer que a gente é jogado na arena né. E a gente não sabe o que fazer" (E2).

São esses conflitos, diferenças e desentendimentos vivenciados pelos gestores, que impulsionam o processo de aprendizagem (Kolb, 1984; Kolb \& Kolb, 2017). O fato de viverem as adversidades do cargo os obrigou a buscarem meios por quais pudessem aprender a lidar com esses problemas. O dilema enfrentado por esses gerentes, cada um diante de um contexto particular, promoveu meios que instigaram a reflexão acerca da prática gerencial, alimentando assim o ciclo do aprendizado. Reis (2011) recorda que a reflexão se desenvolve a partir da exploração, que resulta em novas descobertas e apreciações.

Sabe-se que os domínios da aprendizagem são contínuos, e se expandem, de forma que o que foi aprendido influencia a forma como novas competências são internalizadas (Maximiano, 2014). Assim, a forma como percebemos as novas experiências que vivenciamos, é diretamente afetada pelo modo como processamos as experiências anteriores. Durante as entrevistas foi possível constatar que aqueles sujeitos com um histórico de experiências profissional mais rico, encontraram maior facilidade na transição para se tornarem gerentes gerais:

"Você não vai conseguir fazer um curso de formação que forme um gestor. Quanto mais você passar por cargos dentro do banco, mais fácil é a tua chegada" (E3).

"Como eu passei por diversos locais em agência. (...) nada me surpreendeu" (E4).

As experiências prévias à atividade gerencial são apontadas por Silva (2008) como desenvolvedoras de competências gerenciais e de um aprendizado mais eficaz. São essas as vivenciadas no contexto do trabalho, escola, família, nos relacionamentos pessoais e afetivos, e na vida como um todo. Esse processo de aprendizado não se resume a um momento isolado; é composto pelas mais diversas experiências as quais os indivíduos são submetidos no dia-a-dia. A fala do gerente 6 descreve de forma clara isso: "a gente sempre está aprendendo no dia-a-dia" (E6).

Todos os entrevistados entendiam que já desenvolviam atividades de liderança em contextos fora o ambiente da instituição financeira. Estes visualizaram suas lideranças presentes em atividades dentro do seio familiar, atividades religiosas, acadêmicas, ou mesmo em cargos anteriormente exercidos em empresas fora banco. Percebe-se, portanto, que a aprendizagem "ocorre todo o tempo e em todas as situações em que as 
pessoas agem e interagem - refletem e pensam" (Camillis, 2011, p. 278).

Quanto ao aprendizado que ocorre diariamente na atividade da função gerencial, Hill (1993) afirma que "quando começaram a agir como gerentes, começaram a tornar-se gerentes". Para o entrevistado 1, "a parte prática é o dia-a-dia. Você aprende muito no dia-a-dia" (E1).

Cumpre lembrar que Kolb (1984) e Kolb e Kolb (2017) acreditam que a aprendizagem é melhor entendida como um processo, não como resultado. Este processo possui o caráter de continuidade, sendo fundamentado nas experiências. Essas, por sua vez, encontram nos conflitos e desconfortos que surgem durante o vivenciar a experiência, o combustível para a reflexão e criação de conceitos, levando assim ao indivíduo à necessidade de se adaptar às novas situações. Todo esse processo pôde ser visto claramente nos relatos dos gestores. Observou-se que as situações vivenciadas por esses gestores, que de certa forma abalaram os seus modelos mentais, tornaram-se fontes de aprendizado (Barbieri, 2012).

A teoria da aprendizagem experiencial ressalta a transação entre conhecimento social e pessoal como fonte de aprendizado. Desta forma, o indivíduo aprende com a interação com outros. Durante a pesquisa foi possível observar que a rede de contatos que os indivíduos possuem pode se tornar um diferencial no momento de resolução dos conflitos e construção de aprendizado. Antonello (2011, p.156) apresenta que mudanças duráveis no comportamento dos indivíduos são frutos da "capitalização das experiências individuais e coletivas e da aquisição do conhecimento na ação".

Os sujeitos entrevistados identificaram como fonte de apoio e informação os seus pares (outros gerentes gerais), chefes antigos e atuais, subordinados e colegas em outros setores do banco:

"Não importa se ele é gerente geral ou não, se ele pode te ajudar naquele fator. Você usa muito essa rede de colegas próximos, ou inclusive de outros estados. Se você sabe que aquela pessoa tem uma informação" (E1).

“Tenho pessoas que até hoje... foram meus chefes e ainda hoje chamo de chefe, porque sempre que preciso recorro a eles. (...) então essas pessoas, esses mestres, orientadores contínuos, é quem a gente sempre busca" (E3).

"Tem os colegas de outras agências que são mais experientes. Geralmente a gente troca conhecimento com esses colegas de outras agências" (E5).

Hill (1993) aborda essa rede de relacionamentos como importante fonte de ensinamentos para os gestores. Para os sujeitos dessa pesquisa, a interação social é alternativa para sanar dúvidas, buscar conselhos, orientações e apoio emocional, durante suas atuações como gestores. Essa rede de relacionamento torna-se especialmente útil quando a informação necessária para o desenvolvimento de determinada tarefa não está facilmente disponível, ou quando o problema que surge foge do comum. É nela que o gestor busca inicialmente uma solução, muitas vezes como alternativa a acionar os meios formais da empresa.

Devido a importância que a rede de relacionamentos possui para a prática gerencial, muitos dos gestores entrevistados ressaltaram um curso realizado no Distrito Federal, em que estão presentes gestores de todo o país. Em tal curso, os gerentes são convidados a conhecer diretores e executivos do banco, estimulando a ampliação das interações sociais. Esse fato ressalta a importância que o banco dá às relações informais. Sobre elas, Hill (1993, p.203) destaca:

Os gerentes, além de adquirir habilidades e conhecimentos com o treinamento formal, aumentaram também sua rede de relacionamentos. De fato, os relacionamentos por eles formados durante o treinamento acabaram se constituindo em um importante grupo de suporte. 
Antonello (2011, p.227) por sua vez ressalta também que existem "elementos significativos de aprendizagem formal em situações informais e elementos de informalidade em situações formais. Ambas estão indissoluvelmente inter-relacionadas". Esta relação entre os tipos de aprendizagem demonstra que quando abordamos fontes de aprendizado, os elementos encontrados não excluem ou sobressaem em importância aos demais.

Em resumo, as fontes de aprendizagem apresentadas pelos gestores nessa pesquisa podem ser observadas no quadro a seguir:

\begin{tabular}{|l|l|}
\hline \multirow{2}{*}{ Aprendizagem formal } & $\begin{array}{l}\text { Cursos de graduação e pós-graduação serviram para aquisição de conhecimentos que os } \\
\text { gestores sentiam falta. }\end{array}$ \\
\cline { 2 - 3 } Experiências vivenciadas diariamente & $\begin{array}{l}\text { Cursos formais da empresa foram apontados como ambientes propícios ao aumento das } \\
\text { redes de contatos. }\end{array}$ \\
\hline Problemas e dificuldades encontradas \\
na função & $\begin{array}{l}\text { Dificuldades que surgiam, forçavam aos gerentes uma busca assertiva por soluções ad- } \\
\text { equadas. Esse processo de reflexão, investigação e resolução de problemas foi apontado } \\
\text { como significativo no processo de aprendizado. }\end{array}$ \\
\hline Experiências prévias & $\begin{array}{l}\text { Experiências fora do ambiente gerencial atual foram observadas como valiosas fontes e } \\
\text { competências e facilitadoras do processo de aprendizagem da função gerencial. Sendo } \\
\text { apontado principalmente as experiencias em: ambiente familiar, cursos regulares como } \\
\text { graduação e pós, envolvimento em atividades religiosas, experiencias de trabalhos } \\
\text { prévias. }\end{array}$ \\
\hline Relacionamentos interpessoais & $\begin{array}{l}\text { Relacionamentos com outros gestores, chefes, subordinados ou mesmo com colegas } \\
\text { de outros setores, foram apresentados como fonte de conhecimento, apoio emocional, } \\
\text { orientação e ajuda, diante das dificuldades encontradas na função. }\end{array}$ \\
\hline
\end{tabular}

Quadro 1 - Fontes de aprendizagem apresentadas pelos gestores.

Fonte: dados da pesquisa (2018).

Por fim, indica-se que nesta pesquisa foi possível verificar elementos significativos dos pressupostos da aprendizagem experiencial trazidos por Kolb (1984) e Kolb e Kolb (2017), nos relatos dos gestores entrevistados. Os exemplos de formas de aprendizagem apresentados ressaltam o valor das experiências no processo de aprendizado de gerentes. Essas experiências foram apresentadas como as vivenciadas dentro e fora do contexto gerencial, sendo válidas também aquelas vivenciadas por terceiros e compartilhadas por meio do processo de interação social.

Observou-se, portanto, que, diante das incertezas que envolvem a atividade gerencial, é demando dos gestores a capacidade de se reinventar, buscando formas de aprender constantemente.

\section{Conclusão}

O propósito desta pesquisa foi levantar informações sobre como se dá o processo de aprendizado gerencial, tomando como base gestores de uma grande instituição financeira, em Pernambuco. A revisão teórica aqui efetuada destacou em especial o modelo de aprendizagem experiencial de David Kolb (Kolb, 1984; Kolb \& Kolb, 2017).

Os resultados indicaram que dos gestores é demandado competências específicas, que são frutos de contextos particulares. Observou-se, ainda, que a experiência individual cria os ditames de aprendizado do gestor.

Conhecer como se dá o processo de aprendizado para gestores se torna relevante diante da importância 
que estes profissionais possuem para as organizações. Comumente gerentes são observados como talentos e diferenciais competitivos das organizações. A eles é atribuído a incumbência de gerir os recursos que a empresa possui, buscando formas de maximizar o lucro e alcançar os resultados esperados.

Neste trabalho foi possível, por meio dos relatos de experiências dos gestores, elencar fontes de aprendizagem úteis para formação de competências gerenciais. A função de gerente geral dentro de uma agência bancária é rica em experiências. Diante disso, o modelo de aprendizagem experiencial se torna relevante, ao colocar essas experiências no centro da formação do aprendizado.

A pesquisa buscou ressaltar o valor da aprendizagem formal. Cursos de pós-graduação foram entendidos como complementares a suas atuações, uma vez que trazem, segundo os entrevistados, conhecimentos que estes gestores sentiam falta na prática gerencial. O ambiente da educação formal também foi entendido como fonte de interação social. Essa rede de contatos adquirida durante a realização de cursos formais é compreendida como fonte de apoio e de conhecimentos que facilitam a busca por soluções na prática gerencial.

Os gestores entrevistados entenderam que a principal fonte de aprendizado é a própria prática gerencial. O fato de atuarem como gerentes traz elementos diários que não poderiam ser transmitidos de outra forma. A busca incessante dos gestores pela resolução de percalços vivenciados no dia-a-dia obrigou estes gerentes a refletirem, investigarem, criarem modelos mentais, e implementarem soluções, muitas vezes por meio da tentativa e erro.

Vale salientar que os gestores entenderam que as experiências prévias à função de gerente geral facilitam a transição para o cargo em questão. Os relatos indicaram que muitas dessas experiências haviam ocorrido fora do ambiente da instituição financeira, em locais como a família, igreja, escola, faculdade, outras empresas. Observou-se também que aqueles que haviam desempenhado mais cargos dentro da instituição, encontraram menos dificuldade no processo de aprendizado gerencial.

Relacionamentos interpessoais se mostraram especialmente relevantes como fontes de aprendizado. Seja com outros colegas gestores, subordinados, chefes, ou mesmo com colegas de outros departamentos, essa rede de contatos se torna para os gerentes uma fonte de conhecimentos, onde se busca informações, quando essas não estão facilmente acessíveis nos meios formais.

Em linhas gerais, considera-se que a prática da gestão se apresenta como principal fonte de aprendizado, por trazer elementos únicos e particulares a cada contexto. Experiências pessoais vivenciadas pelos gestores ou aquelas compartilhadas por estes, por meio de suas redes de contatos, são elementos significativos neste processo de aprendizado. Conclui-se, assim, que as organizações devem criar meios pelos quais tais experiências possam ser ressaltadas como fonte de aprendizado, pois somente quando refletidas conscientemente, elas podem se tornarem capazes de gerar competências gerenciais significativas.

\section{Referências}

Antonello, C. S. et al. (orgs.). (2011). Aprendizagem organizacional no Brasil, Bookman, Porto Alegre.

Antonello, C. S. (2011). Contextos do saber: a aprendizagem informal. In: Antonello, C. S.; et al. (orgs.). Aprendizagem organizacional no Brasil. Bookman, Porto Alegre.

Barbieri, U. F. (2012). Gestão de pessoas nas organizações: a aprendizagem da liderança e da inovação, Atlas, 
São Paulo.

Camillis, P. K. (2011). Os saberes no plural: um estudo acerca dos processos de aprendizagem dos trabalhadores que não exercem um papel gerencial. In: Antonello, C. S.; et al. (orgs.). Aprendizagem organizacional no Brasil, Bookman, Porto Alegre.

Closs, L. Q. \& Antonello, C. S. (2011). Ampliando as fronteiras da educação gerencial: é possível uma reflexão crítica? In: Antonello, C. S.; et al. (orgs.). Aprendizagem organizacional no Brasil. Bookman, Porto Alegre.

D’Amelio, M. (2011). Gerentes de diferentes formações e suas trajetórias de aprendizagem. In: Antonello, C. S.; et al. (orgs.). Aprendizagem organizacional no Brasil, Bookman, Porto Alegre.

Gerhardt, T. E. \& Silveira, D. T. (orgs.). (2009). Métodos de pesquisa, Editora da Universidade Federal do Rio Grande do Sul, Porto Alegre.

Gil, A. C. (2002). Como elaborar projetos de pesquisa, 4 ed., Atlas, São Paulo.

Guerra, E. L. A. (2014). Manual: pesquisa qualitativa, Grupo Anima Educação, Belo Horizonte.

Hill, L. A. (1993). Novos gerentes: assumindo uma nova identidade, Makron Books, São Paulo.

Kolb, D. (1984). Experiential learning, Prentice Hall, New Jersey.

Kolb, A. \& Kolb, D. (2017). The experiential educator: principles and practices of experiential learning, EBLS Press, Kaunakakai.

Leite, I. C. B. V. (2011). O aprendizado da função gerencial por meio da experiência. In: Antonello, C. S. et al. (orgs.). Aprendizagem organizacional no Brasil, Bookman, Porto Alegre.

Leite, I. C. B. V.; Godoy, A. S. \& Antonello, C. S. (2006). O aprendizado da função gerencial: os gerentes como atores e autores do seu processo de desenvolvimento. Aletheia, 23, 27-41.

Mapurunga, R. M. R. S. et al. (2016). Programa de desenvolvimento gerencial: estudo de caso na secretaria da fazenda. Pensamento \& Realidade, 31 (1), 37-55.

Marcondes, R. C. (2008). Desenvolvendo pessoas: do treinamento e desenvolvimento à universidade corporativa. In: Hanashiro, Darcy Mitiko Mori, et al. (orgs.). Gestão do fator humano: uma visão baseada em stakeholders, Saraiva, São Paulo.

Maximiano, A. C. A. (2014). Recursos humanos: Estratégia e gestão de pessoas na sociedade global, 1 ed., LTC, Rio de Janeiro. 
Mintzberg, H. (2010). Managing: desvendando o dia a dia da gestão. Bookman, Porto Alegre.

Moraes, L. V. S., Silva, M. A. \& Cunha, C. J. C. A. (2004). Aprendizagem gerencial: teoria e prática. $R A E$ electron., 3 (1), art.7.

Nicolini, A. (2013). Podem indivíduos e suas práticas promover aprendizagem organizacional?. Teoria e Prática em Administração, 3 (1), 19-38.

O Panorama do treinamento no Brasil: fatos, indicadores, tendências e analise.(2017). ABTD. Disponível em: <http://www.integracao.com.br/pesquisa-panorama-do-treinamento-no-brasil-2017.pdf >, acesso em: 10 de mar. de 2017.

Pereima Neto, J. B. \& Pauli, R. C. (2008). O setor bancário no Brasil: transformações recentes, rentabilidade e contribuições à atividade econômica. Economia \& Tecnologia, 12, 121-134.

Reis, D. G. (2011). O papel da reflexão na aprendizagem gerencial. In: Antonello, C. S.; et al. (orgs.). Aprendizagem organizacional no Brasil, Bookman, Porto Alegre.

Santos, E. C. D., Silva, J. K. F., Campos, P. O. \& Cordeiro, G. M. D. S. (2018). Aprendizagem em Ação no Curso de Administração: Intervenção em Organização Cultural na Cidade de Caruaru-PE. Teoria e Prática em Administração, 8 (1), 75-105.

Santos, V. T. \& Cassandre, M. P. (2017). Reflexões sobre água, sabão e conhecimento: aprendizagem organizacional na prática das serventes de limpeza de uma instituição de ensino federal. Teoria e Prática em Administração, 7 (1), 170-206.

Silva, A. B. \& Rebelo, L. M. B. (2006). A gênese da aprendizagem no contexto social: a experiência vivida de gerentes. Revista Alcance, 13 (1), 9-27.

Silva, A. B. O contexto social da aprendizagem de gerentes. (2008). RAM, Rev. Adm. Mackenzie, 9 (6), $26-45$.

Sonnentag, S.; et. al. (2004). Learning at work: training and development. International Review of Industrial and Organizational Psychology, 19, 249-289.

Westbrook, R. B., Teixeira, A. (2010). John Dewey, Editora Massangana, Recife. 